廉泓林, 李卫,冯金超,杨文斌,熊伟,于海蛟,敖铁胜,张明亮,刘雅莉.科尔沈沙地典型固沙人工林地土壤水分时空特征及其对环境因子的响应. 生态学报, 2021,41(20):8256-8265.

Lian H L, Li W, Feng J C, Yang W B, Xiong W, Yu H J, Ao T S, Zhang M L, Liu Y L.Spatiotemporal characteristics of soil moisture and its responses to environmental factors in two typical sand-fixing plantations at the south edge of Horqin Sandy Land. Acta Ecologica Sinica, 2021,41(20):8256-8265.

\title{
科尔沁沙地典型固沙人工林地土壤水分时空特征及其 对环境因子的响应
}

廉泓林 ${ }^{1}$, 李 卫 $^{2}$, 冯金超 ${ }^{2}$, 杨文斌 ${ }^{2}$, 熊 伟 ${ }^{2}{ }^{*}$, 于 海蛟 ${ }^{3}$, 敖铁胜 ${ }^{3}$, 张明亮 ${ }^{4}$, 刘雅莉 ${ }^{2}$

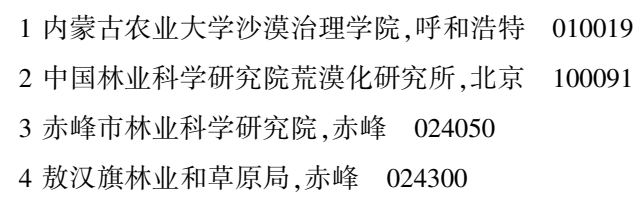

摘要:土壤水分时空动态特征对于干旱地区人工林的可持续经营与管理起着至关重要的作用。以位于科尔沈沙地南缘的樟子 松和柠条固沙人工林为对象, 于 2018 年 11 月一-2019 年 11 月连续观测了林地 0-200 cm 土壤剖面的含水量、温度及微气象因 子,系统分析了土壤水分的时空变化特征及其对环境因子的响应。研究期内,两种林地土壤水分的季节变化可分为冻结期、补 充期、消耗期和稳定期; 依据土壤剖面的水分特征可分为易变层、活跃层和稳定层,但两种林地的分层深度有一定差异。在生长 季内 (5-10 月), 土壤含水量对大气降雨的响应随着土层深度的增加而减弱; 降雨对樟子松人工林 $0-20 \mathrm{~cm}$ 层土壤水分的影 响极显著 $(P<0.01)$, 对柠条人工林 $0-10 \mathrm{~cm}$ 层的影响极显著 $(P<0.01) 、 20-60 \mathrm{~cm}$ 层显著 $(P<0.05)$ 。在土壤冻融周期内 $(2018$ 年 11 月一 2019 年 4 月), 两种林地的土壤均表现为“单向冻结”和“双向融化” 的特点; 土壤温度是影响冻融期内土壤含水量的 关键因素, 两者呈极显著的指数函数关系; 樟子松和柠条人工林土壤的最大冻结深度分别为 $170 \mathrm{~cm}$ 和 $190 \mathrm{~cm}$, 前者 $10 \mathrm{~cm}$ 土层 解冻时间要比后者晚 $11 \mathrm{~d}$, 可能与乔木树冠的遮阴作用有关。潜在蒸散与柠条林 $0-60 \mathrm{~cm}$ 层、樟子松林 $0-20 \mathrm{~cm}$ 和 $200 \mathrm{~cm}$ 层 的土壤水分呈极显著相关 $(P<0.01)$, 而与樟子松林 $60 \mathrm{~cm}$ 和 $160 \mathrm{~cm}$ 层呈显著相关 $(P<0.05)$, 这与树木蒸腾和土壤蒸发等综合 作用有关。研究表明, 由于两种人工林的树种组成、树冠大小、郁闭程度和根系分布等结构特征不同会导致林地土壤水分时空 特征的异质性及其对环境因素响应的差异。

关键词:科尔沁沙地;樟子松;柠条;土壤水分;土壤冻融;潜在蒸散

\section{Spatiotemporal characteristics of soil moisture and its responses to environmental factors in two typical sand-fixing plantations at the south edge of Horqin Sandy \\ Land}

LIAN Honglin ${ }^{1}$, LI Wei ${ }^{2}$, FENG Jinchao ${ }^{2}$, YANG Wenbin ${ }^{2}$, XIONG Wei ${ }^{2, *}$, YU Haijiao ${ }^{3}$, AO Tiesheng ${ }^{3}$, ZHANG Mingliang ${ }^{4}$, LIU Yali ${ }^{2}$

1 College of Desert Control Science and Engineering, Inner Mongolia Agricultural University, Hohhot 010019, China

2 Institute of Desertification Studies, Chinese Academy of Forestry, Beijing 100091, China

3 Institute of Chifeng Forestry Research, Chifeng 024050, China

基金项目: 内蒙古自治区科技重大专项 (2019ZD00301-02) ; 国家林业和草原局林业科技推广项目 (2019-33); 国家重点研发计划项目 (2018YFC0507103); 国家自然科学基金项目(41771306)

收稿日期:2020-12-02; 采用日期:2021-08-16

* 通讯作者 Corresponding author.E-mail: xwcaf@163.com 
4 Bureau of Aohan Banner Forestry and Grassland, Chifeng 024300, China

Abstract : Soil moisture dynamics is essential for the sustainable management of artificial forests in dryland regions. In order to analyze the spatiotemporal characteristics of soil moisture and its responses to environmental factors, soil volumetric water content (SVWC), soil temperature (ST), and micro-meteorological factors were continuously measured in the Pinus sylvestris var. mongolica plantation and Caragana korshinskii plantation stands from November 2018 to November 2019 at the south edge of Horqin Sandy Land. The results showed that the seasonal changes of SVWC in the two stands could be divided into freezing-, replenishment-, consumption-, and stable-phases during the study period. The vertical patterns of SVWC across 0-200 cm soil profile could be classified by variable-, active-and stable-layers. But there was difference in the depth of stratification between the two stands. During the growing season (from May to October), the sensitivity of responses of SVWC to precipitation tended to decrease with increasing soil depth. The influence of rainfall on SVWC at the $0-20 \mathrm{~cm}$ layer of the pine stand was significant $(P<0.01)$, while they were significant for the $0-10 \mathrm{~cm}$ layer $(P<0.01)$ and for the 20-60 cm layer $(P<0.05)$ in the $C$. korshinskii stand, respectively. The soil freeze-thaw cycle (from November 2018 to April 2019) was characterized by unidirectional freezing and bidirectional thawing in the two stands. The SVWC increased exponentially with ST in this period. The maximum of freezing depth of soil profile in the pine and the $C$. korshinskii stands were $170 \mathrm{~cm}$ and $190 \mathrm{~cm}$, respectively; while initiative time of soil thawing at the $10 \mathrm{~cm}$ layer in the pine stand was $11 \mathrm{~d}$ later than that in the $C$. korshinskii stand, which may be attributed to shading effect of tree crown. The SVWC at $0-60 \mathrm{~cm}$ layer in the C. korshinskii plantation and at $0-20 \mathrm{~cm}$ and $200 \mathrm{~cm}$ layers in the pine stand were negatively correlated potential evapotranspiration $\left(E T_{0}\right) \quad(P<0.01)$, while SVWC at the $60 \mathrm{~cm}$ and $160 \mathrm{~cm}$ layers in the pine stand was negatively correlated to $E T_{0}(P<0.05)$, which may be a result from the combining effects of soil evaporation and tree transpiration on SVWC in the two stands. Our results suggest that the spatiotemporal characteristics of soil moisture and their responses to the environmental factors may be ascribed to the difference in the tree composition, canopy structure, and root distribution between the two stands. These findings have potential implications for a better understanding of the influences of the structure of plantations on soil moisture dynamics, and they thus benefit artificial forests management and ecological restoration in the water-limited environments.

Key Words: Horqin Sandy Land; Pinus sylvestris var. mongolica; Caragana korshinskii; soil moisture; soil freeze-thaw ; potential evapotranspiration

土壤水分是陆地生态系统中水分循环和水资源形成与转化等过程的关键环节,也是影响干旱缺水地区众 多植物存活与分布的限制因子 ${ }^{[1-3]}$ 。土壤水分受到气候、土壤、立地条件和植被等诸多自然要素的综合影响, 在时间和空间上表现出强烈的异质性 ${ }^{[4-5]}$ 。由于对土壤水分的时空动态特征研究有助于建立水文过程与生 态格局之间的定量关系,因而它已经成为生态学、水文学等诸多领域关注的热点问题 ${ }^{[6]}$ 。

近几十年内,对干旱区人工植被土壤水分的时空动态特征及其环境影响方面开展了大量研究,并取得了 阶段性成果。一方面,认为降雨量及其分布格局对不同土地利用类型下土壤水分的动态变化有着直接而深刻 的影响。李玉山 ${ }^{[7]}$ 基于降雨发生规律将关西旱塬地区土壤水分的变化划分为冬春水分扩散蒸发阶段、春夏 土壤上层干湿交替阶段、雨季水分恢复阶段和晚秋初冬水分毛管上升蒸发阶段等四个时期; 杨文治 ${ }^{\left[{ }^{8}\right]}$ 认为降 水量的年际和季节变化影响着黄土高原土壤水分的季节性动态; 胡良军等 ${ }^{[9]}$ 认为, 土壤水分的年际变化主要 取决于当年降雨量,且与其季节变化基本一致。另一方面,在气候等诸要素相对一致的情景下,植被类型及其 结构则被认为是影响土壤水分时空变化的关键因素 ${ }^{[10]}$ 。研究表明:树冠截留、树木蒸腾和地表蒸发等过程都 会使土壤水分的分配格局发生改变 ${ }^{[11]}$; 同时,树冠的遮阴作用还会影响土壤水热条件和冻融过程等 ${ }^{[12-13] 。 于 ~}$ 晓娜等 ${ }^{[14]}$ 研究发现: 在相同降雨条件下, 沙地土壤水分的响应深度因植被类型而异; 张北赢等 ${ }^{[15]}$ 认为土壤水 分的剖面形态与分层特征受不同植被水分利用的影响显著; 张孝中等 ${ }^{[16]}$ 则通过比较分析渭北旱塬裸地和农 
田土壤剖面水分变化特征,将其划分为活跃层、次活跃层和相对稳定层。另外,由于人工植被具有短轮伐期和 生长快的特性而比天然植被具有更高的蒸散量 ${ }^{[17]}$, 这可能会导致土壤水分的长期亏缺或者形成土壤干层, 且 其干燥强度因植物种类和生长年限而定 ${ }^{[18-19]}$ 。如, Nan 等 ${ }^{[20]}$ 分析了黄土高原不同林龄刺槐人工林的土壤水 分状况, 发现林分对土壤水分的消耗深度随着年龄的增长而加深。综上所述, 尽管目前国内外学者对区域 (如黄土高原) 的土壤水分研究已经形成了比较完整的体系, 但多仅局限于土壤水分环境的本身问题或者单 一因素的影响, 而缺乏对土壤水分与生态系统结构及其多因素 (水、热等) 之间的系统研究 ${ }^{[9,21]}$ 。同时, 大多 数研究的观测期仅限于生长季, 而对于非生长季中水、热等环境因素的影响 (如冻融作用)也认识不足。

科尔沈沙地是我国的四大沙地之一,过去人工植被的建设使该区生态环境得到了显著改善,但成片固沙 林在生长多年后由于土壤水分亏缺开始出现“小老头树” 甚至导致衰败死亡。令人担忧的是, 相较于黄土区, 该区的砂质土壤持水性低, 人渗快而储水能力低,所以对树木生理需水的调节作用相对较差, 因而对于固沙林 土壤水分时空变化特征的研究则显得尤为重要。樟子松 (Pinus sylvestris var. mongolica) 和柠条 (Caragana korshinskii) 是该区的两个主要造林树种,两者存在着明显的形态差异, 可为不同植被覆盖下土壤水分及其环 境影响研究提供良好的条件。尽管对这两种林分不同密度、林龄和地形条件下的土壤水分变化已有报 道 ${ }^{[22-26]}$, 但还缺乏对不同植被组成条件下土壤水分时空动态及其环境因素影响的综合分析。因此, 本文选择 科尔沁沙地南缘的樟子松固沙林和柠条固沙林为对象, 通过定位观测与统计分析等方法, 来系统认识两种林 地土壤水分时空特征及其对降雨、冻融和潜在蒸散 $\left(E T_{0}\right)$ 的响应, 为该沙区人工植被的建设与生态恢复提供 理论依据和技术支撑。

\section{1 研究区概况}

本试验位于科尔沁沙地南缘的内蒙古自治区赤峰 市敖汉旗东北部治沙林场东胜作业区 $\left(42^{\circ} 47^{\prime} \mathrm{N}, 120^{\circ}\right.$ $\left.17^{\prime} \mathrm{E}\right)$, 见图 1。试验区属温带半干旱季风气候区,海拔 $300-1250 \mathrm{~m}$, 年均气温 $5-7^{\circ} \mathrm{C}$, 年降水量 $310-460$

$\mathrm{mm}$, 年日照时数 $2850-2950 \mathrm{~h}$, 年均风速 $3.8 \mathrm{~m} / \mathrm{s}$, 大风 集中在 3-5 月。土壤以风沙土为主,肥力较为㾑薄,地 下水达 $15 \mathrm{~m}$ 以下。天然植被多为稀疏、低矮的小灌木 和杂草，以黄柳 (Salix gordejevii)、沙蒿 (Artemisia ordosica) 和柠条等为主, 人工植被则以樟子松林、柠条 林和杨柴林 (Hedysarum laeve) 为主。

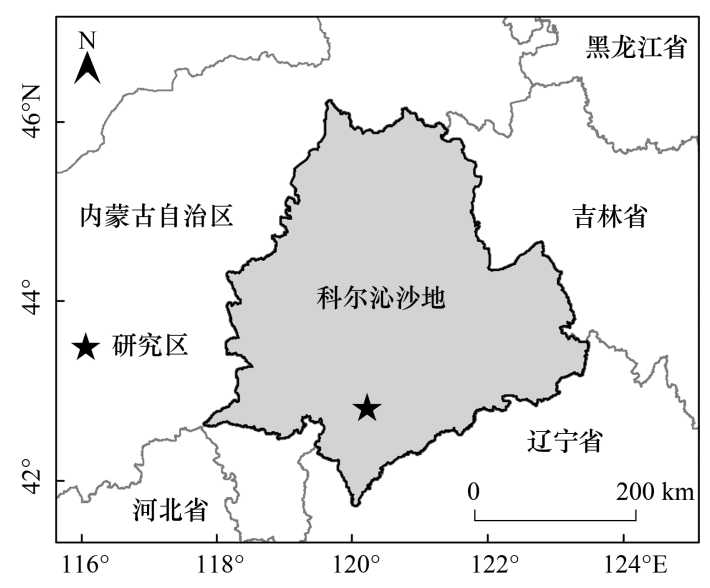

图 1 研究区地理位置图

Fig. 1 Location of the study site at the south edge of Horqin Sandy Land

\section{1 试验设计与测定}

在敖汉旗治沙林场 25 年生的樟子松人工林和 19 年生的柠条人工林内各建立 1 个样地, 大小为 $20 \mathrm{~m} \times$ $20 \mathrm{~m}$; 前者属于固定沙地, 后者为半固定沙地。樟子松人工林: 种植密度 225 株/ $\mathrm{hm}^{2}$, 郁闭度 0.6 , 树高 $(10.07 \pm$ $1.02) \mathrm{m}$, 冠幅 $(3.27 \pm 1.61) \mathrm{m}$, 胸径 $(19.14 \pm 5.02) \mathrm{cm}$, 枝下高 $(3.29 \pm 1.45) \mathrm{m}$ 。柠条人工林: 种植密度 425 株/ $\mathrm{hm}^{2}$, 盖度 $22.55 \%$, 株高 $(1.57 \pm 0.37) \mathrm{m}$, 冠幅 $(2.61 \pm 0.54) \mathrm{m}$, 地径 $(1.63 \pm 0.43) \mathrm{cm}$, 分枝数 $(18 \pm 8)$ 枝。

在两个样地各选择 1 处土壤温度和湿度观测点,在距地表 $10 、 20 、 60 、 120 、 160 \mathrm{~cm}$ 和 $200 \mathrm{~cm}$ 深处用 $\mathrm{ECH}_{2}$ O-5 探头 (Decagon Devices Inc.,USA) 测定土壤各层的体积含水量; 在距地表 $10 、 20 、 60 \mathrm{~cm}$ 和 $200 \mathrm{~cm}$ 深处用 RR10T 探头 (北京雨根科技有限公司, 中国) 测定土壤各层的温度; 在地面 $1.0 \mathrm{~m}$ 高处用 AV-3665R 传感器 (Avalon Inc., USA) 测定降雨量; 用 CR200X 数据采集器 (Campbell Inc., USA) 记录以上数据。在樟子松人工 林林缘空旷处安装气象监测系统 (北京雨根科技有限公司, 中国) 同步测定微气象因子,包括 AV-10T 空气温 
湿度传感器 (12 层辐射罩)、AV-20P 辐射传感器、AV-30WS 风速传感器、AV-30WD 风向传感器, 用数据采集 器 RR-1016( 北京雨根科技有限公司, 中国) 收集数据。数据每 10 min 记录 1 次。

\section{2 数据处理与分析}

用 $\mathrm{Wu}$ 等 ${ }^{[27]}$ 提出的电压值法对测定土壤体积含水量数据进行矫正,模型如下。

$$
y=0.1516-1.501 \times 10^{-3} x+3.218 \times 10^{-6} x^{2}
$$

式中, $x$ 为电压, 单位 $(\mathrm{mv}), y$ 为矫正后体积含水量, 单位 $(\%)$ 。

$E T_{0}$ 采用 Penman-Monteith 模型公式 ${ }^{[28]}$ 进行计算, 具体为:

$$
E T_{0}=\frac{0.408 \Delta\left(R_{\mathrm{n}}-G\right)+\gamma \frac{900}{T+273} U_{2}\left(\mathrm{e}_{s}-e_{a}\right)}{\Delta+\gamma\left(1+0.34 U_{2}\right)}
$$

式中, $E T_{0}$ 为潜在蒸散量 $(\mathrm{mm} / \mathrm{d}) ; \triangle$ 为饱和水汽压 - 温度曲线斜率 $\left(\mathrm{kPa} /{ }^{\circ} \mathrm{C}\right) ; R_{n}$ 为参考作物表面净辐射 $(\mathrm{MJ}$ $\left.\mathrm{m}^{-2} \mathrm{~d}^{-1}\right) ; G$ 为土壤热通量密度 $\left(\mathrm{MJ} \mathrm{m}{ }^{-2} \mathrm{~d}^{-1}\right) ; \gamma$ 为干湿表常数 $\left(\mathrm{kPa} /{ }^{\circ} \mathrm{C}\right) ; T$ 为平均气温 $\left({ }^{\circ} \mathrm{C}\right) ; U_{2}$ 为 $2 \mathrm{~m}$ 高处风 速 $(\mathrm{m} / \mathrm{s}) ; e_{s}$ 为饱和水汽压 $(\mathrm{kpa}) ; e_{a}$ 为实际水汽压 $(\mathrm{kpa})$ 。

原始数据应用 EXCEL 软件进行整理与分析; 土壤水分对降雨、潜在蒸散和冻融的响应分析应用 SPSS 25.0软件进行分析; 图 2-8 应用 Origin 2019 软件进行绘制。

\section{3 结果与分析}

\section{1 气象要素变化特征}

\subsection{1 大气降雨}

研究期 2018 年 11 月 14 日至 2019 年 11 月 14 日) 内共发生了 58 次降雨,总降雨量 $236.6 \mathrm{~mm}$;降雨集中 在 7-9 月, 累计 $133.6 \mathrm{~mm}$, 占总降雨量 $56.47 \%$ 。图 2 表明: $\leqslant 5 \mathrm{~mm}$ 降雨 39 次, 累计 $47.2 \mathrm{~mm}$, 占总降雨量 $19.95 \%$;5-10 mm 降雨 11 次, 累计 $72 \mathrm{~mm}$, 占总降雨量 $30.43 \%$; 10-20 mm 降雨 7 次, 累计 $97.2 \mathrm{~mm}$, 占总降 雨量 $41.08 \%$; $\geqslant 20 \mathrm{~mm}$ 降雨 1 次, 累计 $20.2 \mathrm{~mm}$, 占总降雨量 $8.54 \%$ 。

\subsection{2 潜在蒸散 $\left(E T_{0}\right)$}

研究期内 $E T_{0}$ 的季节变化趋势总体呈现出单峰值曲线, 在 5 月 24 日达到峰值 $(8.2 \mathrm{~mm} / \mathrm{d}$ ) ; 冬季 (2018 年 12 月- 2019 年 2 月)、春季 ( $3-5$ 月)、夏季 (6-8 月) 和秋季 $\left(9-11\right.$ 月) 的平均 $E T_{0}$ 分别为 $0.49 、 3.47 、 5.28$ 、 $1.72 \mathrm{~mm} / \mathrm{d}$, 见图 3。总体来看,生长季 (5-10 月) $E T_{0}$ 维持在较高的水平, 累计 $789.2 \mathrm{~mm}$, 占总 $E T_{0}$ 的 $78.34 \%$ 。

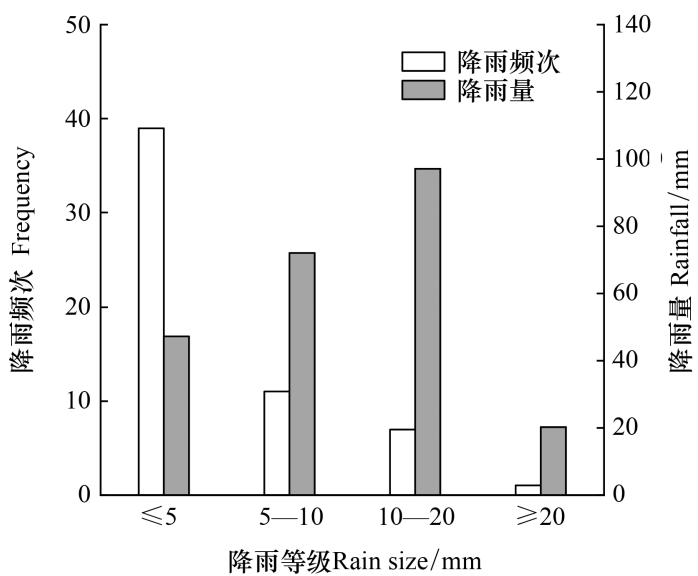

图 2 研究期内降雨频次及雨量大小分布

Fig.2 Frequency distributions of gross rainfall percentages and amounts for the 58 rainfall events during the study period

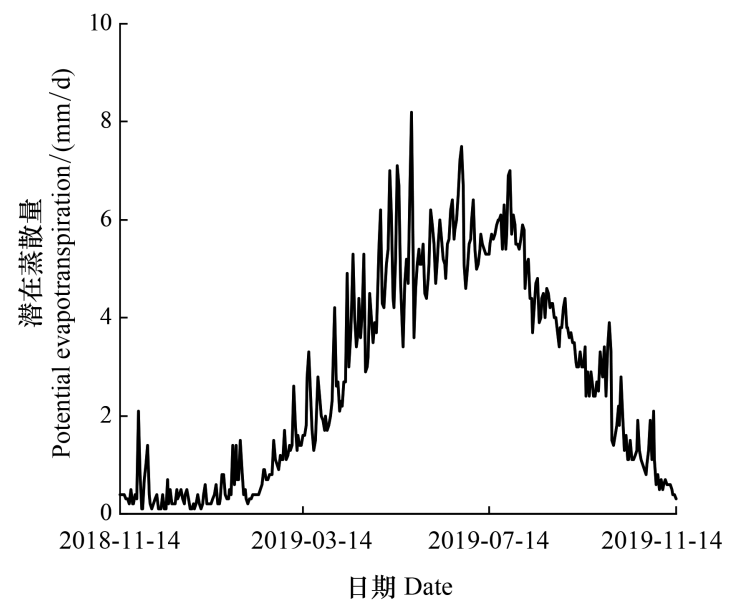

图 3 试验区林地日潜在蒸散量的季节变化

Fig.3 Seasonal changes in potential evapotranspiration $\left(E T_{0}\right)$ during the study period 


\subsection{3 土壤温度}

樟子松人工林和柠条人工林地土壤剖面各层温度均呈现出与 $E T_{0}$ 相似的季节变化特征,分别于冬季和夏 季达到最低值和最高值, 见图 4。表 1 表明:林地各层土壤温度与大气温度均呈现出极显著的正相关关系 $(P<$ $0.01)$ 。柠条人工林地土壤剖面各层相关系数略高于同层的樟子松人工林地,这可能与樟子松人工林的树冠 遮阴作用有关。

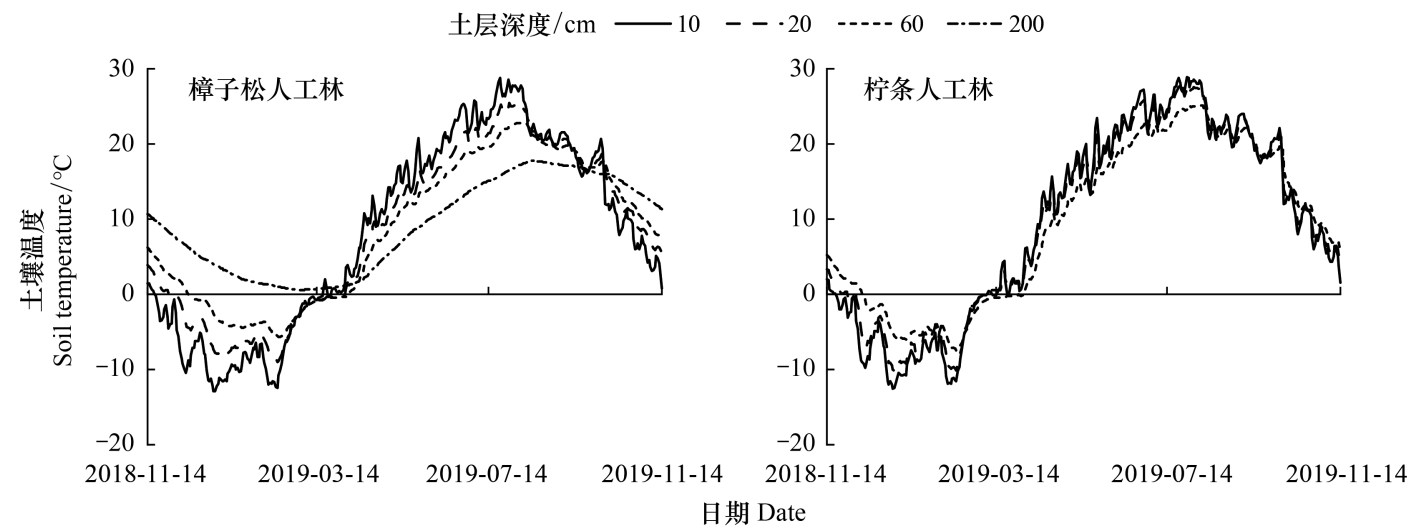

图 4 樟子松和柠条人工林地各层土壤温度的季节变化

Fig.4 Seasonal changes in soil temperature at the different layers in $P$. sylvestris var. mongolica and $C$. korshinskii stands

表 1 樟子松和柠条人工林地各层土壤温度与大气温度的相关关系

Table 1 Correlation between air temperature and soil temperature at the different layers in $P$. sylvestris var. mongolica and $C$. korshinskii stands

\begin{tabular}{|c|c|c|c|c|}
\hline \multirow{2}{*}{$\begin{array}{l}\text { 样地 } \\
\text { Plot }\end{array}$} & \multicolumn{4}{|c|}{ 土层深度 Soil depth } \\
\hline & $10 \mathrm{~cm}$ & $20 \mathrm{~cm}$ & $60 \mathrm{~cm}$ & $200 \mathrm{~cm}$ \\
\hline 樟子松人工林 P. sylvestris var. mongolica plantation & $0.938^{* *}$ & $0.895^{* *}$ & $0.846^{* *}$ & $0.653^{* * *}$ \\
\hline 柠条人工林 $C$. korshinskii plantation & $0.947^{* *}$ & $0.928^{* *}$ & $0.888^{* *}$ & - \\
\hline
\end{tabular}

$* *$ 极显著 $(P<0.01)$

\section{2 土壤含水量的时空变化特征}

由图 5 知,在研究期内樟子松和柠条人工林地土壤水分的季节变化可划分为冻结期 (2018 年 11 月下 旬一2019 年 2 月)、补充期 (3-4 月)、消耗期 (5-9 月)和稳定期( 10-11 月上旬)。在冻结期内冻结的土壤 剖面含水量变化稳定,基本在 5\%以下; 在补充期内, 随着气温回升、解冻,各层土壤含水量范围分别达到 $4.6 \%-12.3 \%$ (樟子松林) 和 $5.3 \%-12.0 \%$ (柠条林) ; 在消耗期内, 由于树木旺盛生长和蒸腾以及降雨的补给 等综合作用导致了土壤水分的剧烈波动, 其值在 2.6\%-12.2\% (樟子松林) 和 1.0\%-13.9\% (柠条林) 之间; 稳 定期内树木逐渐进人休眠期, 加之蒸发较低而使土壤含水量稳定,樟子松林维持在 $2.5 \%-7.4 \%$, 柠条林在 $1.8 \%-7.0 \%$ 之间。图 6 表明:在冻结期、补充期樟子松林地平均含水量要显著高于柠条林地 $(P<0.05)$, 消耗 期内差异不显著 $(P>0.05)$, 而稳定期内柠条林显著高于樟子松林 $(P<0.05)$ 。

为量化认识两种林地土壤剖面水分的垂直动态分布, 分析了生长季内土壤各层含水量变化的特征 (表 $2)$,并结合图 5, 可将其大致分为 3 个层次, 即: 1$)$ 易变层 $(0-20 \mathrm{~cm})$, 土壤水分等值线最为密集,表明变化十 分强烈, 其含水量分别为 2.9\%-11.5\% (樟子松林) 和 3.5\%-14.0\% (柠条林)。2) 活跃层(樟子松林 20-100 $\mathrm{cm}$ 和 160-200 cm, 柠条林 20-180 cm), 土壤水分等值线相对密集,受水分人渗和根系吸水等过程影响而使 含水量变化活跃,其中,樟子松林又可分为活跃层 $(20-100 \mathrm{~cm}$, 含水量 2.6\%-9.3\%) 及次活跃层 (160-200 $\mathrm{cm}$, 含水量 $6.4 \%-12.2 \%$ ) ; 柠条林含水量范围为 $1.0 \%-10.5 \%$ 。3) 稳定层 (樟子松 100-160 cm, 柠条 180$200 \mathrm{~cm})$, 樟子松和柠条林各层土壤含水量分别为 $3.1 \%-4.3 \%$ 和 $5.5 \%-6.8 \%$ 。 


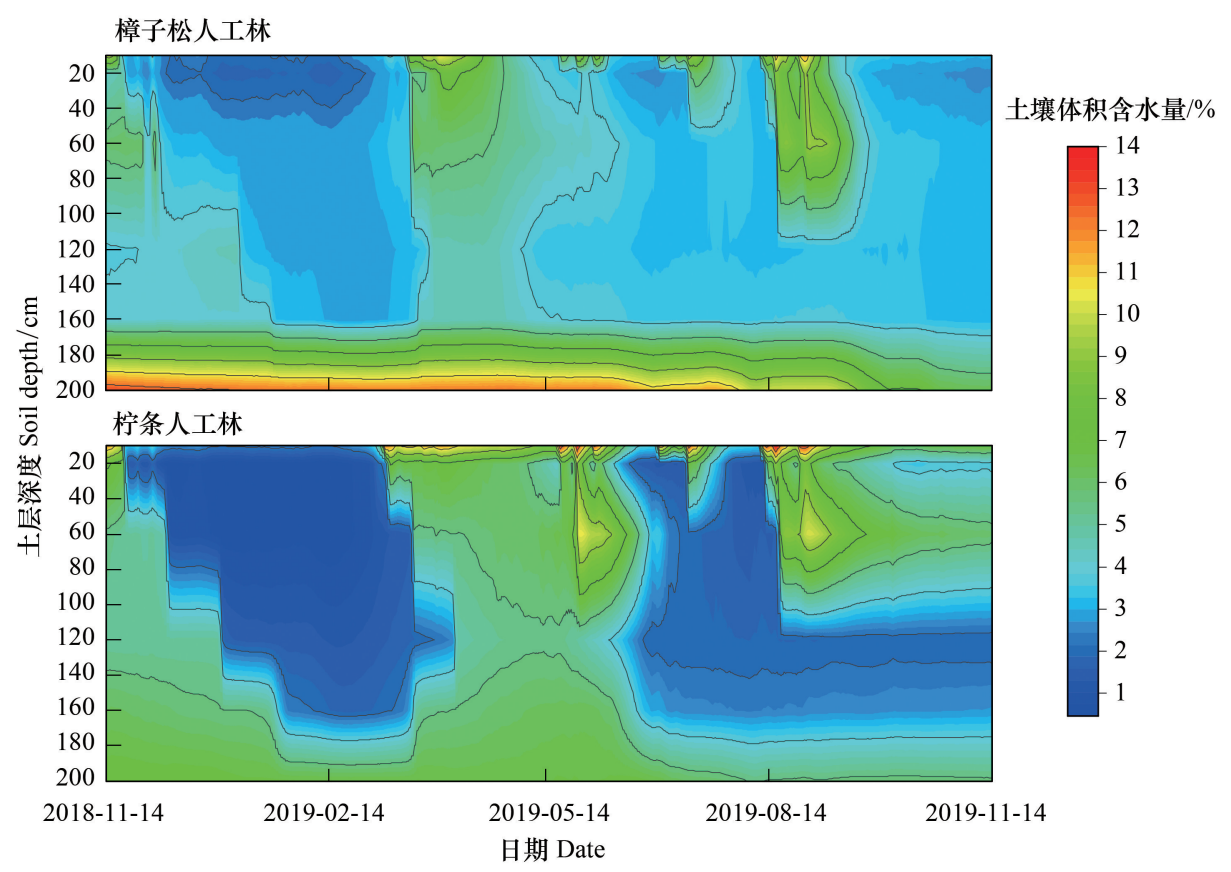

图 5 樟子松和柠条人工林地土壤水分的时空变化特征

Fig.5 Characteristics of spatiotemporal variation of soil moisture in $P$. sylvestris var. mongolica and $C$. korshinskii stands

\section{3 土壤水分对环境因素的响应}

\subsection{1 大气降雨的响应}

在生长季内,两种林地对大气降雨的响应均随土层 深度加深而减弱, 见图 7。受降雨影响, 林地 10-60 cm 层土壤水分波动较为频繁, 而 $120-200 \mathrm{~cm}$ 层较为稳定 且存在滞后响应。为进一步量化两者之间的关系, 选择 林地同期内累计降雨量与土壤水分的变化量进行相关 性分析, 结果表明: 生长季内, 降雨事件对樟子松林 0 $20 \mathrm{~cm}$ 层土壤含水量影响极显著 $(P<0.01)$; 对柠条林 $0-10 \mathrm{~cm}$ 层土壤含水量影响极显著 $(P<0.01), 20-60$ $\mathrm{cm}$ 层影响显著 $(P<0.05)$; 而对其余各层均无显著影响 $(P>0.05)$ ，见表 3 。

\subsection{2 冻融作用的响应}

研究期内, 樟子松人工林和柠条人工林土壤含水量 均表现出 “冻结迅速减少、融化迅速增加”的冻融循环 模式,但两种林地在冻融周期及其影响深度有一定差 异。冬季当土壤剖面各层温度降至 $0^{\circ} \mathrm{C}$ 后, 土壤水分开 始自表层向下 “单向冻结”; 樟子松林和柠条林最大冻 结深度分别为 $170 \mathrm{~cm}$ 和 $190 \mathrm{~cm}$ 左右 (图 5)。进人春 季随太阳辐射增强和土温上升,地表的热量收人大于支

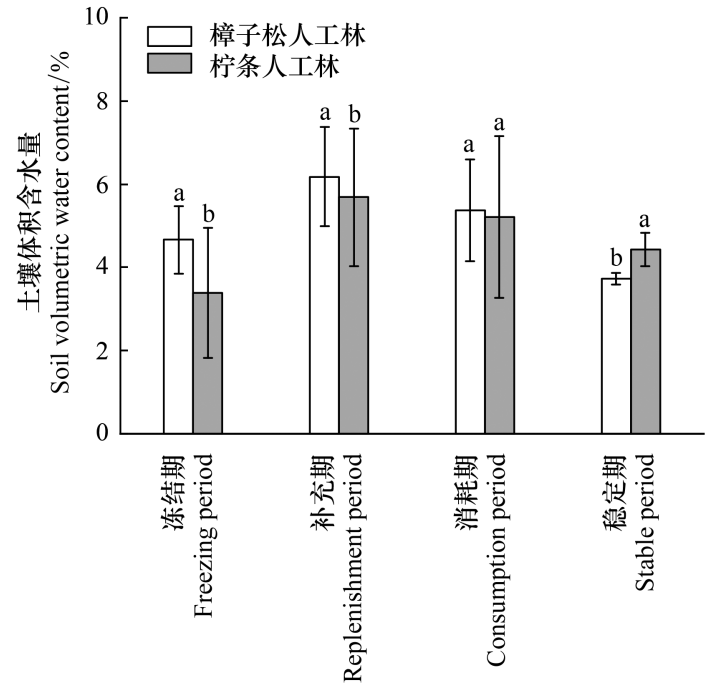

图 6 不同时期樟子松和柠条人工林地土壤体积含水量的对比 分析

Fig.6 Comparison of soil volumetric water content during the different phases between $P$. sylvestris var. mongolica stand and $C$. korshinskii stand

不同小写字母表示两处林地的土壤体积含水量存在显著差异 $(P<$ $0.05)$

出, 同时土壤深层的热量也开始向上传导,故而表现出由上层、下层到中层 “双向融化” 的土壤解冻特征,这可 从地表和深层土壤含水量的增加要早于中间层 $(120 \mathrm{~cm})$ 得到印证。樟子松林 $10 \mathrm{~cm}$ 层土壤解冻时间比柠条 


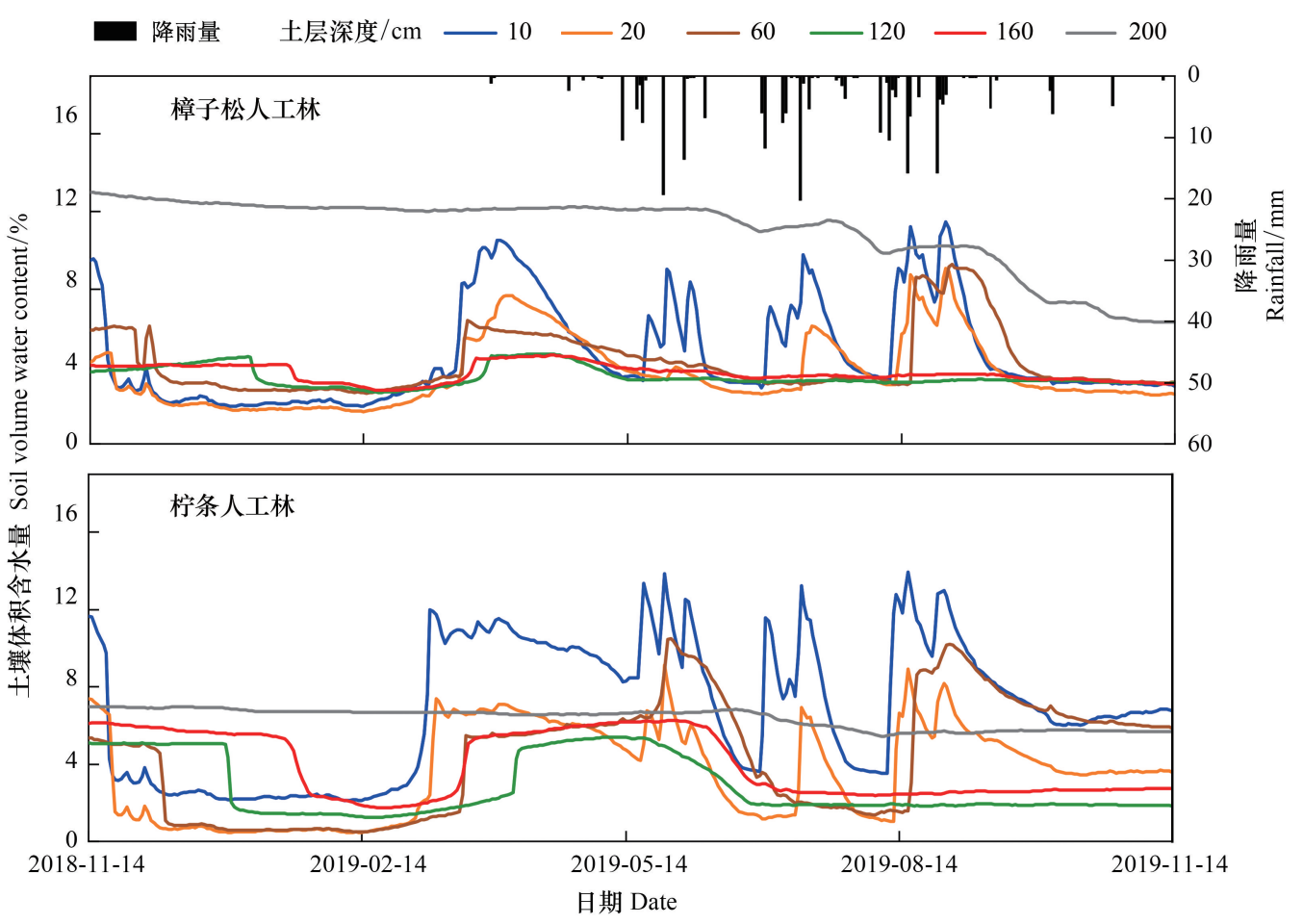

图 7 樟子松和柠条人工林地各层土壤含水量对大气降雨的响应

Fig.7 Response of soil moisture at the different layers to precipitation in P. sylvestris var. mongolica and $C$. korshinskii stands

林晚 $11 \mathrm{~d}$,可能与前者树冠遮阴引起的地表温度差异有关。图 8 分析了冻融循环期内 $0^{\circ} \mathrm{C}$ 以下土壤温度与含 水量之间的关系, 结果表明: 在冻融期内, 土壤含水量随着土壤温度增加而呈极显著的指数增加 $(P<0.01)$ 。

表 2 樟子松和柠条人工林地土壤剖面各层含水量的变化特征

Table 2 Characteristics of seasonal changes in soil moisture at the different layers across 0-200 cm profile in $P$. sylvestris var. mongolica and $C$. korshinskii stands

\begin{tabular}{|c|c|c|c|c|c|c|}
\hline \multirow[b]{2}{*}{$\begin{array}{c}\text { 土层深度 } \\
\text { Soil depth/cm }\end{array}$} & \multicolumn{3}{|c|}{ 樟子松人工林 P. sylvestris var. mongolica plantation } & \multicolumn{3}{|c|}{ 柠条人工林 C. korshinskii plantation } \\
\hline & $\begin{array}{c}\text { 平均值 } \\
\text { Average value }\end{array}$ & $\begin{array}{c}\text { 标准差 } \\
\text { Standard deviation }\end{array}$ & $\begin{array}{l}\text { 变异系数 } \\
\text { Coefficient of } \\
\text { variation/\% }\end{array}$ & $\begin{array}{c}\text { 平均值 } \\
\text { Average value }\end{array}$ & $\begin{array}{c}\text { 标准差 } \\
\text { Standard deviation }\end{array}$ & $\begin{array}{l}\text { 变异系数 } \\
\text { Coefficient of } \\
\text { variation/\% }\end{array}$ \\
\hline 10 & 5.13 & 2.31 & 45.03 & 8.13 & 2.77 & 34.07 \\
\hline 20 & 3.99 & 1.55 & 38.85 & 4.22 & 1.96 & 46.45 \\
\hline 60 & 4.46 & 1.82 & 40.81 & 5.86 & 2.80 & 47.78 \\
\hline 120 & 3.29 & 0.13 & 3.95 & 2.65 & 1.30 & 49.06 \\
\hline 160 & 3.56 & 0.22 & 6.18 & 3.53 & 1.52 & 43.06 \\
\hline 200 & 10.24 & 1.81 & 17.68 & 6.07 & 0.46 & 7.58 \\
\hline
\end{tabular}

表 3 樟子松和柠条人工林地土壤含水量变化与降雨量的相关分析

Table 3 Correlation between soil moisture and rainfall in $P$. sylvestris var. mongolica and $C$. korshinskii stands

\begin{tabular}{lrccccc}
\hline 样地 & \multicolumn{5}{c}{ 相关系数 Correlation coefficient } \\
\cline { 2 - 7 } Plot & $10 \mathrm{~cm}$ & $20 \mathrm{~cm}$ & $60 \mathrm{~cm}$ & $120 \mathrm{~cm}$ & $160 \mathrm{~cm}$ & $200 \mathrm{~cm}$ \\
\hline 樟子松人工林 P. sylvestris var. mongolica plantation & $0.964^{* *}$ & $0.858^{* *}$ & 0.734 & -0.64 & 0.268 & 0.697 \\
柠条人工林 C. korshinskii plantation & $0.948^{* *}$ & $0.915^{*}$ & $0.838^{*}$ & 0.365 & 0.279 & 0.665 \\
\hline
\end{tabular}

$* *$ 极显著 $(P<0.01), *$ 显著 $(P<0.05)$ 


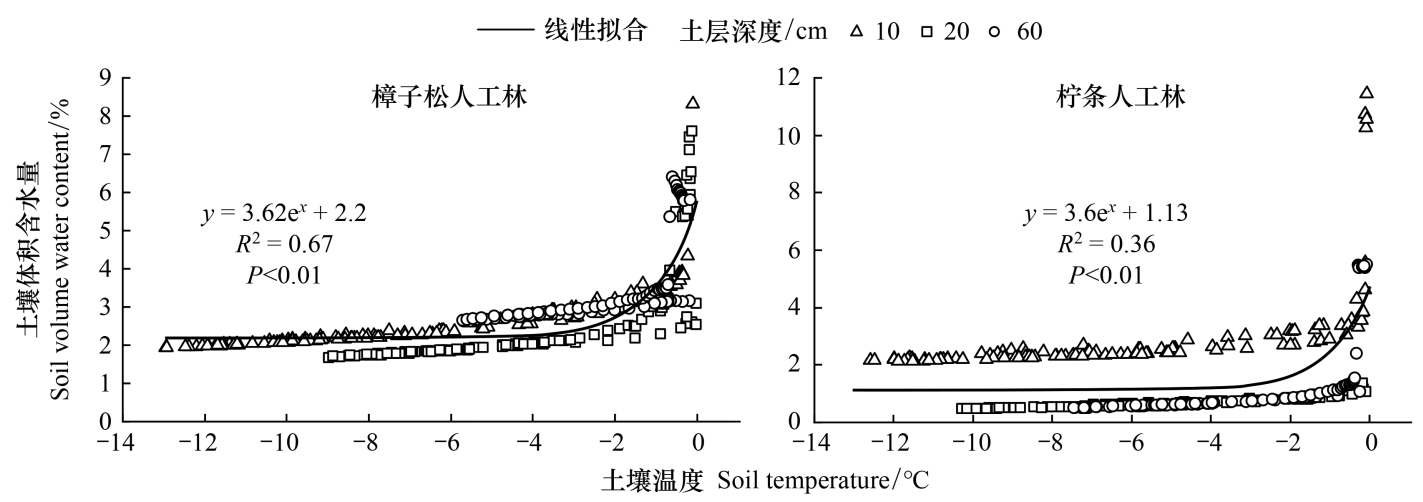

图 8 冻融循环期内樟子松和柠条人工林地各层土壤含水量与土壤温度的相关关系

Fig.8 Relationships between soil temperature and soil moisture at different layers in the $P$. sylvestris var. mongolica and $C$. korshinskii stands during soil freeze-thaw period

\subsection{3 $E T_{0}$ 的响应}

$E T_{0}$ 表示某一地区水分供应不受限制时下垫面可能达到的最大蒸发量,它可通过控制树木蒸腾、土壤蒸 发和冻融等作用而间接影响土壤含水量。用生长季内两场降雨间隔期内的土壤含水量变化量与同期 $E T_{0}$ 进 行相关分析,结果表明: $E T_{0}$ 与土壤含水量呈负相关关系,与柠条林 0-60 cm 层和樟子松林 0-20 cm、200 cm 层的土壤含水量呈极显著相关 $(P<0.01)$, 与樟子松林 $60 \mathrm{~cm}$ 和 $160 \mathrm{~cm}$ 层的土壤含水量呈显著相关关系 $(P<$ $0.05)$ ，见表 4 。

表 4 樟子松和柠条人工林地土壤含水量变化与 $E T_{0}$ 的相关分析

Table 4 Correlation between soil moisture and potential evapotranspiration in $P$. sylvestris var. mongolica and $C$. korshinskii stands

\begin{tabular}{|c|c|c|c|c|c|c|}
\hline \multirow{2}{*}{$\begin{array}{l}\text { 样地 } \\
\text { Plot }\end{array}$} & \multicolumn{6}{|c|}{ 土层深度 Soil layer $/ \mathrm{cm}$} \\
\hline & 10 & 20 & 60 & 120 & 160 & 200 \\
\hline 樟子松人工林 $P$. sylvestris var. mongolica plantation & $-0.948^{* *}$ & $-0.817 * *$ & $-0.460^{*}$ & -0.233 & $-0.664^{*}$ & $-0.836^{* *}$ \\
\hline 柠条人工林 $C$. korshinskii plantation & $-0.914^{* *}$ & $-0.746^{* *}$ & $-0.536^{* *}$ & -0.408 & -0.458 & -0.451 \\
\hline
\end{tabular}

$* *$ 极显著 $(P<0.01), *$ 显著 $(P<0.05)$

\section{4 讨论}

\section{1 土壤水分的时空动态特征}

本研究将樟子松和柠条人工林的土壤水分季节变化划为冻结期、补充期、消耗期和稳定期,虽然划分的阶 段略有差异,但总体规律与其它文献相似 ${ }^{[29-30]}$ 。除消耗期外,两种林地土壤含水量的动态变化呈现出显著性 差异,说明由于树种组成与密度等结构的不同导致了两种林地土壤水分时空动态的差异。与樟子松相比较, 柠条的树冠较小、冠层郁闭程度较低,因而冻结期内,受气温影响其林地的土壤温度更低而导致含水量显著偏 低; 在消耗期内, 虽然柠条单株的蒸腾耗水量要低于樟子松,但较大的密度 ( 425 株 $\left./ \mathrm{hm}^{2}\right)$ 所影响的林分总蒸腾 量会使两种林地土壤水分的差异不显著; 进人稳定期后,树木生长对土壤水分的需求逐渐降低,且由于柠条林 地表干沙层 (约 $5 \mathrm{~cm}$ 厚) 的存在减缓了土壤蒸发速率 ${ }^{[31]}$, 从而导致了其土壤水分含量大于樟子松林。

在研究期内,樟子松固沙林和柠条固沙林土壤剖面各层土壤水分的动态变化存在着明显差异,尤其是其 活跃层分布的差别较为明显。对于樟子松人工林而言,主要存在两个土壤水分变化的活跃层:20-100 $\mathrm{cm}$ 层 和 160-200 cm 层。一方面,樟子松的主要根系分布在 $100 \mathrm{~cm}$ 土层以内 ${ }^{[32]}$, 生长季内由于降雨人渗、土壤蒸 发、树木根系吸水与树木蒸腾等综合作用会使该层土壤含水量剧烈变化; 另一方面,本研究发现 $200 \mathrm{~cm}$ 土层 含水量的变化仍较为活跃并总体呈现出明显的下降趋势,其值从期初 $12.2 \%$ 下降至期末 $6.4 \%$ 。这是由于观 
测期总降雨量仅为 $236.6 \mathrm{~mm}$, 远小于年均降雨量 $310 \mathrm{~mm}$, 这使得其主要根系分布层的土壤水分远远无法满 足树木蒸腾耗水量需求, 从而来消耗深层土壤的水分所致 ${ }^{[24]}$, 这与在章古台地区樟子松林地的研究结果是基 本一致的 ${ }^{[33]}$ 。相对而言, 柠条人工林的活跃层集中在 20-180 cm 范围之内, 而研究期内 $200 \mathrm{~cm}$ 土层含水量 总体保持在稳定水平, 这说明柠条虽然是深根性灌木树种, 与樟子松相比较而言, 其对土壤水分的消耗量相对 较低,但同时也说明浅层和深层土壤水分都是该树种重要的水分来源 ${ }^{[34]}$ 。

\section{2 土壤水分对环境因子的响应}

本研究中, 樟子松人工林和柠条人工林地土壤水分对天然降雨的响应均随土层加深而减弱,这与前人的 研究是一致的 ${ }^{[35]}$ 。樟子松人工林 $10 \mathrm{~cm}$ 土层含水量对降雨的响应要比柠条人工林更为敏感, 这可能是由于 后者样地中存在干沙层会阻挡一部分雨水人渗的缘故 ${ }^{[36]}$ 。在 20-60 cm 土层, 樟子松人工林土壤含水量对 于天然降雨的响应要弱于柠条林,可能与前者具有较大树冠和郁闭度从而具有较高的冠层截留量有关。

本研究发现樟子松人工林和柠条人工林地土壤冻融现象均表现为“单向冻结” 和“双向融化” 的特征,这 与陈仁升等的研究结果是基本一致的 ${ }^{[37]}$ 。本研究表明: 与柠条灌木林相比较, 樟子松人工林土壤最大冻结深 度为 $170 \mathrm{~cm}$ ( 比柠条林浅 $20 \mathrm{~cm}$ ) 且 $10 \mathrm{~cm}$ 层土壤解冻时间较柠条林延长 $11 \mathrm{~d}$, 这可能与樟子松林地内有一定 厚度枯枝落叶层的保温以及高大树冠的遮阴作用有关。据 Chen 等报道, 与农田相比较, 人工林由于高大树冠 的遮阴作用会使冻结土壤消融出现滞后, 同时会避免冻土层在冻融周期内出现大的波动 ${ }^{[13]}$, 这与本研究结论 是相似的。

本研究中 $E T_{0}$ 的最高值出现在 $5 、 6$ 月份, 可能与 $7 、 8$ 月份降雨频繁而太阳辐射较低而有关, 这与李霞等 人研究结果相一致 ${ }^{[38]}$ 。 $E T_{0}$ 与樟子松林和柠条林浅层的土壤水分含量相关性密切, 说明了由于 $E T_{0}$ 增加所导 致的树木蒸腾和土壤蒸发的双重作用而显著影响了土壤的含水量。然而, $E T_{0}$ 对樟子松人工林地 $160-200$ $\mathrm{cm}$ 土层含水量也存在着极为密切的相关性 $(P<0.01)$, 这是由于在欠水年 $100 \mathrm{~cm}$ 以上土壤水分无法满足樟子 松林分较强的蒸腾量, 从而导致可能消耗深层 $(200 \mathrm{~cm})$ 土壤水分的情况 ${ }^{[24,33]}$, 但这还需更为深人地研究。

\section{5 结论}

(1) 樟子松和柠条人工林地土壤水分的季节变化可划分为冻结期 (2018 年 11 月下旬一2019 年 2 月)、补 充期 (3-4 月)、消耗期 (5-9 月) 和稳定期 (10-11 月上旬); 其剖面在垂直方向上可分为: 易变层 (0-20 cm 层)、活跃层 (樟子松 20-100 cm 层和 160-200 cm 层,柠条 20-180 cm 层) 和稳定层 (樟子松 100-160 cm 层, 柠条 180-200 cm 层)。

(2) 两种林地对大气降雨的响应均呈现出随土层深度加深而减弱的趋势, 但响应深度有所不同。降雨对 樟子松林 $0-20 \mathrm{~cm}$ 层的影响极显著 $(P<0.01)$; 对柠条林 0-10 cm 层影响极显著 $(P<0.01), 20-60 \mathrm{~cm}$ 层显 著 $(P<0.05)$; 其余各层均不显著。

(3) 两种林地土壤表现为 “单向冻结” 和 “双向融化” 的特点, 但两者冻融周期和对土壤影响深度有一定 差异。樟子松林和柠条林最大冻结深度分别为 $170 \mathrm{~cm}$ 和 $190 \mathrm{~cm}$ 左右; 樟子松林 $10 \mathrm{~cm}$ 层土壤解冻时间较柠 条林延长 $11 \mathrm{~d}$ 。在冻融期内, 土壤温度是影响土壤含水量的关键因素, 两者呈极显著的指数增加关系。

(4) $E T_{0}$ 对两种林地的土壤含水量呈负相关关系, 其中与柠条林 $0-60 \mathrm{~cm}$ 和樟子松林 $0-20 \mathrm{~cm} 、 200 \mathrm{~cm}$ 层呈极显著相关 $(P<0.01)$, 与樟子松林 $60 \mathrm{~cm}$ 和 $160 \mathrm{~cm}$ 层呈显著相关关系 $(P<0.05)$ 。

\section{参考文献 (References) :}

[ 1 ] 李新荣, 张志山, 黄否, 王新平. 我国沙区人工植被系统生态-水文过程和互馈机理研究评述. 科学通报, 2013, 58(5/6): 397-410.

[ 2 ] Xia J, Ning L K, Wang Q, Chen J X, Wan L, Hong S. Vulnerability of and risk to water resources in arid and semi-arid regions of West China under a scenario of climate change. Climatic Change, 2017, 144(3): 549-563.

[ 3 ] 杨大文, 丛振涛, 尚松浩, 倪广恒. 从土壤水动力学到生态水文学的发展与展望. 水利学报, 2016, 47(3): 390-397.

[ 4 ] 邱扬, 傅伯杰, 王军, 陈利顶. 黄土丘陵小流域土壤水分的空间异质性及其影响因子. 应用生态学报, 2001, 12(5): 715-720. 
[ 5 ] Gwak Y, Kim S. Factors affecting soil moisture spatial variability for a humid forest hillslope. Hydrological Processes, 2017, 31(2): 431-445.

[ 6 ] 李新乐, 吴波, 张建平, 辛智鸣, 董雪, 段瑞兵. 白刺沙包浅层土壤水分动态及其对不同降雨量的响应. 生态学报, 2019, 39(15)： 5701-5708.

[ 7 ] 李玉山. 关中旱塬地区小麦丰产的土壤水分条件. 中国农业科学, 1962,3(5): 1-9.

[ 8 ］ 杨文治. 黄土高原土壤水分状况分区(试拟)与造林问题. 水土保持通报，1981，(2): 13-19.

[ 9 ] 胡良军, 郡明安. 黄土高原植被恢复的水分生态环境研究. 应用生态学报, 2002, 13(8): 1045-1048.

[10 ] Chen L D, Huang Z L, Gong J, Fu B J, Huang Y L. The effect of land cover/vegetation on soil water dynamic in the hilly area of the loess plateau, China. CATENA, 2007, 70(2): 200-208.

[11 ] Vivoni E R, Rinehart A J, Méndez-Barroso L A, Aragón C A, Bisht G, Cardenas M B, Engle E, Forman B A, Frisbee M D, Gutiérrez-Jurado H A, Hong S H, Mahmood T H, Tai K, Wyckoff R L. Vegetation controls on soil moisture distribution in the Valles Caldera, New Mexico, during the North American monsoon. Ecohydrology, 2008, 1(3): 225-238.

[12] Marks D, Winstral A. Comparison of snow deposition, the snow cover energy balance, and snowmelt at two sites in a Semiarid Mountain Basin. Journal of Hydrometeorology, 2001, 2(3): 213-227.

[13] Chen L X, Chen Z S N, Jia G D, Zhou J, Zhao J C, Zhang Z Q. Influences of forest cover on soil freeze-thaw dynamics and greenhouse gas emissions through the regulation of snow regimes: a comparison study of the farmland and forest plantation. Science of the Total Environment, 2020, 726: 138403 .

[14] 于晓娜, 李恩贵, 黄永梅, 李小雁. 毛乌素沙地油蒿 (Artemisia ordosica) 群落土壤水分动态特征. 中国沙漠, 2015, 35(3): 674-682.

[15] 张北赢,徐学选, 白晓华. 黄土丘陵区不同土地利用方式下土壤水分分析. 干旱地区农业研究, 2006, 24(2) : 96-99.

［16］张孝中, 韩仕峰, 李玉山. 渭北旱原土壤水分动态规律研究. 干旱地区农业研究, 1990, (4) : 27-36.

[17] Yu Z, Liu S R, Wang J X, Wei X H, Schuler J, Sun P S, Harper R, Zegre N. Natural forests exhibit higher carbon sequestration and lower water consumption than planted forests in China. Global Change Biology, 2019, 25(1): 68-77.

［18］李玉山. 黄土区土壤水分循环特征及其对陆地水分循环的影响. 生态学报, 1983, 3(2): 91- 101.

[19] Schwärzel K, Zhang L L, Montanarella L, Wang Y H, Sun G. How afforestation affects the water cycle in drylands: a process-based comparative analysis. Global Change Biology, 2020, 26(2) : 944-959.

[20] Nan G W, Wang N, Jiao L, Zhu Y M, Sun H. A new exploration for accurately quantifying the effect of afforestation on soil moisture: a case study of artificial Robinia pseudoacacia in the Loess Plateau (China). Forest Ecology and Management, 2019, 433: 459-466.

[21] 邵明安, 贾小旭, 王云强, 朱元骏. 黄土高原土壤干层研究进展与展望. 地球科学进展, 2016, 31(1): 14-22.

[22] 冯伟, 杨文斌, 党宏忠, 李卫, 韩辉, 宋晓东, 张学利. 不同密度樟子松固沙林土壤水分特征. 水土保持通报, 2015, 35(5): 189-194.

[23] 潘占兵, 李生宝, 郭永忠, 王占军, 温学飞. 不同种植密度人工柠条林对土壤水分的影响. 水土保持研究, 2004, 11(3) : 265-267.

[24] 魏晓婷, 雷泽勇, 韩辉. 章古台沙地不同林龄樟子松人工林土壤水分研究. 干旱区资源与环境, 2016, 30(6): 115-121.

[25] 莫保儒, 蔡国军, 杨否, 芦娟, 王子婷, 党宏忠, 王多锋, 戚建莉. 半干旱黄土区成熟柠条林地土壤水分利用及平衡特征. 生态学报, 2013, 33(13) : 4011-4020.

[26] 间德仁, 黄海广, 胡小龙, 袁立敏. 樟子松固沙林土壤水分动态对降雨人渗的响应. 水土保持通报, 2017, 37(6): 328-333.

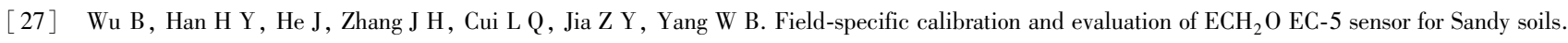
Soil Science Society of America Journal, 2014, 78(1) : 70-78.

[28] Allen R G, Pereira L S, Raes D, Smith M. Crop Evapotranspiration: Guidelines for Computing Crop Water Requirements. FAO Irrigation and Drainage Paper No 56. Rome: FAO, 1998.

[29］杨佩国, 李保国, 吕贻忠. 毛乌素沙地典型地形断面土壤水分动态. 干旱区研究, 2004, 21(4): 333-337.

[30］伍永秋, 张健枫, 杜世松, 哈斯额尔敦, 黄文敏. 毛乌素沙地南缘不同活性沙丘土壤水分时空变化. 中国沙漠, 2015, 35(6): 1612-1619.

[31] 刘新平, 张铜会, 赵哈林, 何玉惠, 云建英, 李玉强. 流动沙丘干沙层厚度对土壤水分蒸发的影响. 干旱区地理, 2006, 29(4): 523-526.

[32］宋立宁, 朱教君, 郑晓. 基于沙地樟子松人工林衰退机制的营林方案. 生态学杂志, 2017, 36(11): 3249-3256.

[33] 韩辉, 张学利, 党宏忠, 徐贵军, 张晓, 王斯形, 陈帅, 张柏习. 科尔沈沙地南缘樟子松林蒸腾强度的年际变化及与降水、地下水位间的 关系. 林业科学, 2020, 56(11): 31-40.

[34] 王胜. 水蚀风蚀交错区典型乔灌树种蒸腾耗水特征研究 [D]. 北京: 中国科学院大学 (中国科学院教育部水土保持与生态环境研究中 心), 2019.

[35] 赵荣玮, 张建军, 李玉婷, 张艳婷, 田宁宁. 晋西黄土区人工林地土壤水分特征及其对降雨的响应. 水土保持学报, 2016, 30 (1): 178- 183 .

[36] 杨文斌, 唐进年, 梁海荣, 党宏忠, 李卫. 我国典型沙漠 (地) 流动风沙土的深层渗漏量及动态变化. 中国科学: 地球科学, 2014, 44(9): 2052-2061

[37] 陈仁升, 康尔泗, 吉喜斌, 阳勇, 张智慧, 卿文武, 白生云, 王连东, 孔庆柱, 雷有宏, 裴宗喜, 王军. 黑河源区高山草甸的冻土及水文过 程初步研究. 冰川冻土, 2007, 29(3): 387-396.

[38］李霞, 刘廷胥, 段利民, 王冠丽, 童新, 周亚军, 杨晓君. 科尔沈湿草甸参考作物蒸散发模拟分析. 中国沙漠, 2020, 40(2): 134-143. 